\title{
Biomass pellet production with industrial and agro-industrial waste
}

\author{
J. C. A. R. Claro \& D. Costa-Gonzalez \\ Universidade de Trás-os-Montes e Alto Douro, Portugal
}

\begin{abstract}
Based on a patented process for the treatment and reprocessing of waste and effluents from olive oil and cork industries (such as two-phase olive husks cork powder), new research has been carried out incorporating other industrial waste. In previous research, using only olive oil and cork waste, biomass pellets were obtained having high calorific values $(20.6 \mathrm{MJ} / \mathrm{kg}$ and $22.2 \mathrm{MJ} / \mathrm{kg})$, low moisture $(8.9 \%)$ and relatively a low ash percentage (3.9\%). Several new formulations and their relevance to the calorific value were now tested using other waste or byproducts. The potential inclusion of olive leaves from the olive oil industry, grape husks and grape seeds from the winery industry and chestnut shells (outer shell and inner skin) from the chestnut industry has been analysed. This process will contribute to solving environmental problems resulting from the discharge of those waste and effluents and to create a viable and profitable alternative to their storage and/or deposition in landfill. The increase of other biomass sources for these types of process is extremely important from an environmental and economic management point of view. This research shows that the use of different types of raw materials as biomass sources (giving different pellets formulations) results in a different final product with different physical and chemical characteristics that may improve its quality.

Keywords: biomass pellets, olive waste, cork waste, food industry waste.
\end{abstract}

\section{Introduction}

Company strategies are now becoming increasingly focused on factors for increasing productivity which also profess to be "environmentally-friendly". The reprocessing of waste and by-products is therefore at the top of corporate concerns. 
Given the strategic importance that the olive oil sector represents for Mediterranean countries, these production and transformation units must not disregard this new attitude.

In this context, this process could be important to biomass industries and constitutes a very important technological platform internally for olive oil companies, launching them into a strategic framework characterised by an increase in productivity, a cleaner and more environmentally-friendly production that will become an important contribution to the sustainability of the sector.

Olive oil can be obtained by three processes each of which includes the phases of weighing, washing of the olives, warehousing and milling (or grinding). The traditional process involves a pressing phase of the olives followed by a decantation/centrifugation which produces husks and olive mill wastewater in addition to the olive oil.

More modern methods include, a "beating" process replacing the pressing, followed by an "extraction" in horizontal centrifuges. Water is added during these last two phases to facilitate the separation of the olive oil. These more modern methods consist of:

- Phase 1: Here the effluents are the same as those in the traditional method (husks and olive mill wastewater which are separate);

- Phase 2: This process results in a single effluent, known in the industry as "humid husks" or a "paste" (the result of the husks mixed together with the olive mill wastewater).

Most of the olive oil currently produced uses the two production processes above. There are also production units known as "husk oil extraction units" which extract some of the remaining olive oil from the "husks" or "humid husks".

In any case and irrespective of the method used, all the units generate waste and effluents which are harmful to the environment [1-3] and extensive research has been carried out on this issue [4-6].

Some existing treatment and/or reprocessing systems for effluents from olive oil production units are: irrigation of agricultural soils, lagooning, concentration through evaporation, physical/chemical processes, thermal processes, biological processes.

On the other hand, as far as the cork industry residues are concerned, (mainly cork powder, particles less than $0.25 \mathrm{~mm}$ in size), which are considered as industrial residues (Code 030199 of European Waste List), problems associated with drainage and storage have been verified, as well as the harmful environmental effects caused by them. The study by the Industrial Association of the District of Aveiro ("Multi-Sector Study on the Area of Environment") in 2000 must be highlighted here (AIDA [7]). This study explicitly refers to the fact that "The production of cork powder is, inclusively, responsible for some physiographical changes verified in the Council of Santa Maria da Feira (small valleys that disappear due to the continual deposition of cork dust in them)". However, the cork powder has had its main use as a combustible fuel for producing energy (burns in kilns), with a small fraction being used for filling in 
corks of a lower quality, in the linoleum factory and in the control of soils (Gil [8]).

Therefore it can be seen that none of the processes already known represent a sole and universal solution for the effective treatment and reprocessing of waste and effluents from olive oil production units and which at the same time is a solution for the drainage and efficient reprocessing of cork industry waste.

The process presented in this paper can be applied to the treatment of effluents and waste from olive oil production units in the following situations:

- Through the separate treatment of the waste and the effluent (husks and olive mill wastewater);

- Through the joint treatment of the waste and the effluent (humid husks). In this sense the process can be applied to any type of olive oil production installation whether it is using the traditional production system or the modern two-phase or three-phase production system. Therefore this approach could be an important contribution to a complete and universal solution for the efficient treatment of such residues and effluents. In fact, the known technologies only present part of the solution to the problem and some infer high implementation costs.

\section{Methods and materials}

\subsection{Sample preparation}

In sample preparation, two-phase olive husks and industrial waste or byproducts, such as olive leaves, grape husks, grape seeds and chestnut shells are used; these were previously turned into powder, in a grinding process using a sieve with a $1 \mathrm{~mm}$ mesh.

The powder, which results from the solid materials, is mixed mechanically with the two-phase olive husks generating a pulp material or paste that later is extruded and passes through a drying system to obtain a dried solid product.

\subsection{Tested formulations}

The olive mill waste (two-phase olive husks) were mixed with the different industrial waste, testing two formulations with 8 and $15 \%$ (wt/wt) of each industrial waste powder.

\subsection{Gross Calorific Value determination}

The Gross Calorific Value (GCV) was determined for each formulation by calorimetric analysis performed with an AC600SHC Semi-Automatic Calorimeter (Leco) in the Chemistry Department of Trás-os-Montes e Alto Douro University (UTAD) in Vila Real, Portugal. 


\section{Results and discussion}

The process utilises grinded industrial waste, namely olive leaves from the olive oil industry, grape husks and grape seeds from the winery industry and chestnut shells (outer shell and inner skin) from the chestnut industry, mixed mechanically with the effluents and/or waste from olive oil production units creating a pulp material or paste that can be used, after drying, as a source of energy fuel. After the mixing, the paste can be extruded in the required form (e.g. pellets or briquettes) and brought to convenient moisture in a dryer. The obtained dried solid product (fig. 1) has a calorific value about $20 \%$ higher than wood pellets or chips and a low percentage of moisture and ashes. With this very high calorific value, the recovery of the dry product as pellets, chips, briquettes or logs for burning in a biomass boiler will be extremely feasible.

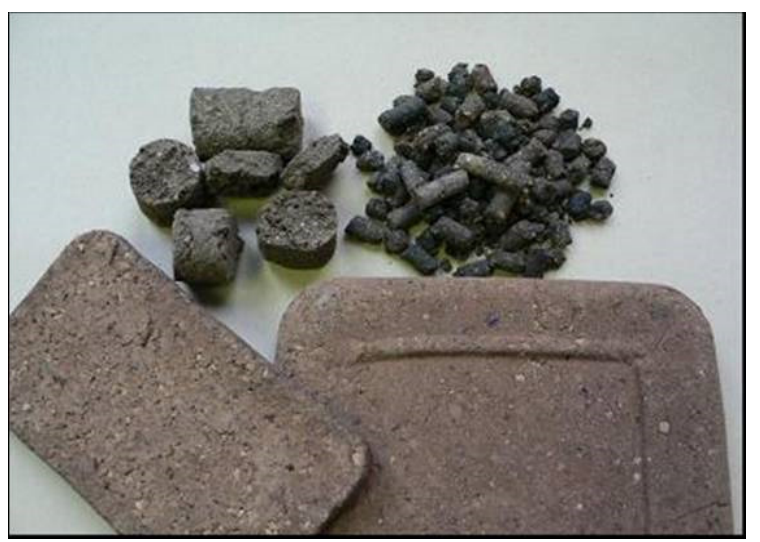

Figure 1: Biomass samples obtained by the described process.

In table 1, the results of the gross calorific value for the different formulations of the biomass pellets obtained by this process can be seen.

These results show that the use of different types of raw materials as biomass sources for pellet production could be adopted based on this process and a similar range of calorific values are obtained $(21.3-23.0 \mathrm{MJ} / \mathrm{kg}$ ) comparatively to those with the cork powder. Different formulations lead to different final products with different physical and chemical characteristics that may define and improve its quality. Additionally the pellets biomass does not release unpleasant odours and has good mechanical resistance. Nevertheless, more research is needed to design pellets with suitable properties for specific applications and achieve all standards and norms required in the market.

\section{Conclusions}

This approach offers an important contribution to a complete solution for the residues and/or effluents of the olive oil production units and the end-product 
obtained does not create a new environmental problem. The final product of this process has a high calorific value, about $20 \%$ higher relatively to wood pellets or chips and constitutes a material with great potential as biomass fuel. This process also presents a solution to an environmental problem which is duly identified and regulated by European standards and national laws.

Table 1: Gross Calorific Value (GCV) from biomass samples of olive mill waste (two-phase olive husks) with 8 and 15\% (wt/wt) of different kinds of industry waste.

\begin{tabular}{lccc}
\hline \multirow{2}{*}{ Industry biomass waste } & \multicolumn{3}{l}{ Gross Calorific Value $(\mathrm{GCV}) \mathrm{MJ} \mathrm{kg}^{-1}$} \\
\cline { 2 - 4 } & $\begin{array}{c}\text { Sample } \\
\mathrm{n}^{\mathbf{0}}\end{array}$ & $8 \%(\mathrm{wt} / \mathrm{wt})$ & $\begin{array}{c}15 \% \\
(\mathrm{wt} / \mathrm{wt})\end{array}$ \\
\hline Olive leaves & 1 & 22,5390 & 22,0738 \\
& 2 & 22,4635 & 22,2682 \\
& 3 & 22,6383 & 22,1495 \\
\cline { 2 - 4 } & Average & $\mathbf{2 2 , 5 4 6 9}$ & $\mathbf{2 2 , 1 6 3 8}$ \\
\cline { 2 - 4 } & S.D.* & 0,0609 & 0,0696 \\
\hline Grape husks & 1 & 22,8858 & 23,0456 \\
& 2 & 22,8237 & 22,9319 \\
& 3 & 22,7819 & 22,7606 \\
\cline { 2 - 4 } & Average & $\mathbf{2 2 , 8 3 0 5}$ & $\mathbf{2 2 , 9 1 2 7}$ \\
\cline { 2 - 4 } & S.D.* & 0,0369 & 0,1014 \\
\hline Grape seeds & 1 & 22,8982 & 23,0718 \\
\cline { 2 - 4 } & 2 & 23,0390 & 23,1672 \\
\cline { 2 - 4 } & 3 & 22,8415 & 22,8296 \\
\cline { 2 - 4 } & Average & $\mathbf{2 2 , 9 2 6 2}$ & $\mathbf{2 3 , 0 2 2 9}$ \\
\cline { 2 - 4 } & S.D.* & 0,0752 & 0,1288 \\
\hline Chestnut shell & 1 & 21,9291 & 21,2779 \\
& 2 & 22,1941 & 21,3670 \\
& 3 & 22,0296 & 21,3221 \\
\hline & Average & $\mathbf{2 2 , 0 5 0 9}$ & $\mathbf{2 1 , 3 2 2 3}$ \\
\cline { 2 - 4 } & S.D.* & 0,0954 & 0,0298 \\
\hline
\end{tabular}

*S.D. = Standard Deviation.

This enables the difficulties and disadvantages of the existing technologies to be overcome, especially those related to high implementation/execution costs and to the fact that they do not translate into a global solution, contributing only partial and/or one-off solutions to the problem.

In addition to all the environmental benefits, the process enables a product that has a commercial value to be obtained and which may constitute an attractive financial compensation for the olive oil production units and for the 
cork transformation units. Additionally, this process allows water recuperation by condensation of the steam produced in the drying process.

\section{References}

[1] Ben Sassi, A., Ouazzani, N., Walker, G.M., Ibnsouda, S., El Mzibri, M. \& Boussaid, A., Detoxification of olive mill wastewaters by Moroccan yeast isolates. Biodegradation, 19(3), pp. 337-346, 2008.

[2] Andreozzi, R., Canterino, M., Di Somma, I., Lo Giudice, R., Marotta, R., Pinto, G. \& Pollio, A., Effect of combined physico-chemical processes on the phytotoxicity of olive mill wastewaters. Water Research, 42(6-7), pp. 1684-1692, 2008.

[3] Morillo, J. A., Aguilera, M., Antízar-Ladislao, B., Fuentes, S., RamosCormenzana, A., Russell, N.J. \& Monteoliva-Sánchez, M., Molecular microbial and chemical investigation of the bioremediation of two-phase olive mill waste using laboratory-scale bioreactor. Applied Microbiology and Biotechnology, 79(2), pp. 309-31, 2008.

[4] Gómez, A., Zubizarreta, J., Rodrigues, M., Dopazo, C. \& Fueyo, N., An estimation of the energy potential of agro-industrial residues in Spain. Resources, Conservation and Recycling, 54(11), pp. 972-984, 2010.

[5] Russo, C., Cappelleti, G.M. \& Nicoletti, G.M., LCA of energy recovery of the solid waste of the olive oil industries. 6th International Conference on LCA in the Agri-Food Sector, Zurich, 2008.

[6] Roig, A., Cayuela, M.L. \& Sánchez-Monedero, M.A., An overview on olive mill wastes and their valorization methods. Waste Management, 26, pp. 960 969, 2006.

[7] AIDA - Associação Industrial do Distrito de Aveiro, Estudo Multi-Sectorial na Área do Ambiente, 61p, 2000.

[8] Gil, L., Cork powder waste: an overview. Biomass and Energy, 13, pp. 5961, 1997. 